\title{
Improved 800 Meter Running Results Through The Use of Exercise Methods and Endurance
}

\author{
Jhoni Melvin Tahapary ${ }^{1}$, Moch Asmawi ${ }^{2}$ and James Tangkudung ${ }^{3}$ \\ \{jhontahapary62@gmail.com ${ }^{1}$ \} \\ Universitas Negeri Jakarta, Jakarta, Indonesia ${ }^{1,2,3}$ \\ Universitas Pattimura Ambon, Indonesia ${ }^{1}$
}

\begin{abstract}
The appearance of an athlete must be planned and arranged programmatically, directed at achieving peak performance in a sport that must be achieved with a systematic and planned effort. Besides that, to increase running speed based on three forms of muscle endurance and lung endurance training methods, the author tries to compare the three methods that are most effective for increasing muscle endurance and endurance of the heart-lung. The method used in this study is a field experiment method. In accordance with the problems and research objectives to be achieved, this study uses an experimental method with factorial design: 2 x 3 Data analysis techniques using ANOVA. The results are to improve the results of the 800 meter run on Unpatti Ambon FKIP Penjaskesrek students can be improved through fartlek training methods, continuous training methods, and interval training methods by controlling endurance first.
\end{abstract}

Keywords: athlete, running, exercise method, endurance

\section{Introduction}

The appearance of an athlete must be planned and arranged programmatically, directed at achieving peak performance in a sport that must be achieved with a systematic and planned effort. The relationship between coach and athlete is viewed as central to effective coaching and in turn athletic performance and development [1]-[4]. A coach-athlete relationship takes understanding and commitment; it can be dynamic in nature, and changes within the interactions of the coach-athlete conditional state of affairs [5]. This also applies to athletic sports specifically for medium distance running numbers.

Coach-athlete interactions are recognized as being particularly significant, not only in terms of fostering athletes' technical and performance capabilities, but also with respect to promoting character development, sport enjoyment and prolonged participation (Jackson, et al., 2011). Coaching develops people through improving their performance [6]-[9].

Based on observations in the field, the performance of mid-distance and long-distance runners in Maluku has declined further, especially in the mid-distance run (800, 1500 meters), even up to the implementation of the XIX National Sports Week held in West Java in 2016, the Maluku contingent did not lower its runners in the numbers of 800 and 1500 meter medium distance due to the time reached at the time the selection did not meet the target provided by the regional KONI, besides that the athletes who were included in the Pre qualification PON did not reach the time which was determined by PB PASI, thus no middle distance runners participated in the West Java PIX XIX. Maluku Province in West Java PON XIX in Athletics sports only included athletes in the men's 400-meter run, the 400-meter men's goal 
(Gaining gold medals in women's numbers and men's bronze medals), and 4x400 meters of male relay daughter (Received a silver medal in the women's number and bronze medal in the men's number), and the Son's Long Jump (Achieved a bronze medal).

The resources of trainers who have not fully received the development of science and technology training in achievement sports, resulting in athlete achievement training is not balanced with the potential of the athlete itself. To optimize mechanics in the medium distance run, it requires a contribution of good physical condition [10]. Physical conditions can be formed through various forms of training of the many forms of physical condition training and training methods, the authors want to see and know the method of training physical conditions in this case the fartlek training method, continuous training methods, and methods interval training that can increase muscle endurance and cardiovascular endurance in increasing the 800 meter run result. Besides that, to increase running speed based on three forms of muscle endurance and lung endurance training methods, the author tries to compare the three methods that are most effective for increasing muscle endurance and endurance of the heart-lung

\section{Method}

The method used in this study is a field experiment method. Experimental metods according to [11] are observations carried out by artificial conditions where the conditions are made and regulated by the researcher. According to experimental research [12], [13] is a research that is conducted striclty to find out the causal relationship between variabels. One of the main characteristics in experimental research is the existence of treatments that are worn on the subject or object of the researcher. Research design or research design is a plan and structure of investigations arranged so that researchers can obtain answers to their research questions [14]. In accordance with the problems and research objectives to be achieved, this study uses an experimental method with factorial design: 2 × 3 . Data analysis techniques using ANOVA.

\section{Result}

Data description is a general description of the data of each variable in the study. The data will provide an overview of the conditions of each variable that is examined. The data obtained from the results of the 800 meter run test, namely acyl run, obtained based on travel time/run. The results of the 800 meter run test are the results of exercise using several approaches to exercise methods (Fartlek, Continuous, and Interval) and endurance. The exercise method consists of Fartlek exercise methods, Continuous exercise methods, and Interval exercise methods. Data that can be described consists of six groups, namely: 1) Data from 800 meters run which are trained with Fartlek exercise methods that have high durability. 2) The 800 meter run data that is trained with the Continuous exercise method which has high durability. 3) 800 meter running data that is trained with Interval exercise g methods that have high durability. 4) Data from the 800 meter run were trained with the Fartlek exercise method which has low endurance ability. 5) 800 meter run data that is trained with the Continuous exercise method which has low durability. 6) Data from the 800 meter run are trained with Interval exercise methods that have low durability. Data for each group are presented as a mean as a measure of concentration, standard deviation as a measure of distribution, frequency distribution table, and histogram. 


\subsection{Results of an 800 meter run Group of Fartlek Exercise Methods (A1)}

Based on the research data of the 800 meter run (Y), the lowest score was 123.05 , the highest score was 128.66 so that the range was 5.61. From the statistical calculation, the average value of 125.16 standard deviation (s) was 1.28 and the variance was obtained. amounting to 2.60 and to provide an overview of the frequency distribution of the 800 meter run $(\mathrm{Y})$, the frequency distribution can be arranged as follows:

Table 1. 800 meter running frequency distribution list in the Fartlek Exercise Method (A1)

\begin{tabular}{|c|c|c|c|c|c|}
\hline \multicolumn{6}{|c|}{ group } \\
\hline No & Value Interval & $\mathrm{F}$ & $\mathrm{X}$ & F.X & F Relative \\
\hline 1 & $123.05-124.16$ & 7 & 123.61 & 865.242 & $35.00 \%$ \\
\hline 2 & $124.17-125.28$ & 3 & 124.73 & 374.184 & $15.00 \%$ \\
\hline 3 & $125.29-126.41$ & 5 & 125.85 & 629.25 & $25.00 \%$ \\
\hline 4 & $126.42-127.53$ & 4 & 126.97 & 507.888 & $20.00 \%$ \\
\hline \multirow[t]{2}{*}{5} & $127.54-128.66$ & 1 & 128.10 & 128.099 & $5.00 \%$ \\
\hline & TOTAL & 20 & & & $100 \%$ \\
\hline
\end{tabular}

From the results of the 800 meter run test which was collected from 20 sample people in the Fartlek (A1) exercise method group of Unipatti FKIP Penjaskesrek students, it turns out the score range $123.05-124.16$ there are 7 people or $35 . \%$, scores $124.17-125.28$ there are 3 person or $15 . \%$, score $125.29-126.41$ there are 5 people or $25 . \%$, a score of $126.42-127.53$ there are 4 people or $20 . \%$ and a score of $127.54-128.66$ there is 1 person or $5 \%$. Thus, from the results of the 800 meter run test which was collected from 20 samples in the continuous exercise method group (A2) Unipatti FKIP Penjaskesrek students, it turns out the score range $123.03-123.88$ there are 4 people or $20 \%$, the score $123.89-124.74$ there are 3 people or $15 \%$, score $124.75-125.60$ there are 4 people or $20 \%$, a score of $125.61-126.46$ there are 4 people or $20 \%$ and a score of $126.47-127.33$ there are 5 or $25 \%$.

\subsection{0 meter run result Interval Exercise Method Group (A3)}

Based on the research data of the 800 meter run $(Y)$ the lowest score was 123.05 , the highest score was 128.65 so that the range was obtained 5.60 From the statistical calculation obtained an average value of 125.33 standard deviation (s) of 1.08 and a variance of 3.11 and to provide an overview of distribution the frequency of the 800 meter run (Y) can be arranged in the frequency distribution as follows:

Table 2. 800 meter running frequency distribution list in the Interval Exercise Method group (A3)

\begin{tabular}{cccccc}
\hline No & Value Interval & F & X & F.X & F Relative \\
\hline 1 & $123.05-124.16$ & 7 & 123.61 & 865.235 & $35.00 \%$ \\
2 & $124.17-125.28$ & 4 & 124.73 & 498.9 & $20.00 \%$ \\
3 & $125.29-126.40$ & 3 & 125.85 & 377.535 & $15.00 \%$ \\
4 & $126.41-127.52$ & 3 & 126.97 & 380.895 & $15.00 \%$ \\
5 & $127.53-128.65$ & 3 & 128.09 & 384.27 & $15.00 \%$ \\
& TOTAL & 20 & & & $100 \%$ \\
\hline
\end{tabular}


From the results of the 800 meter run test which was collected from 20 samples in the Interval exercise method group (A3) students of FKIP Unpatti Penjaskesrek, it turns out the score range is $123.05-124.16$ there are 7 people or $35 . \%$, scores $124.17-125.28$ there are 4 people or $20 . \%$, score 125.29 - 126.40 there are 3 people or $15 . \%$, a score of $126.41-127.52$ there are 3 people or $15 . \%$, and a score of 127.53 - 128.65 there are 3 people or $15 . \%$. From the results of the 800 meter run test collected from 10 samples in the Fartlek exercise group with the ability of High Durability (A1B1) students of FKIP Unpatti Penjaskesrek, it turns out the score range $123.05-123.70$ there are 4 people or $40 \%$, the score $123.71-124.36$ there are 3 people or $30 \%$, scores $124.37-125.01$ there are 1 person or $10 \%$, and a score of 125.02 125.68 there are 2 people or $20 \%$.

\subsection{0 meter Running Result Group of Interval Exercises with High Durability}

(A3B1).

Based on the research data of the 800 meter run on 10 students in the Interval training method group with High Endurance ability (A3B1) the lowest score was 124.14 and the highest score was 128.65 so the range was 4.51 . From the statistical calculation, the average deviation was 126.46 ( $\mathrm{s}$ ) amounting to 1.58 and variance of 2.51 and to provide an overview of the frequency distribution of the 800 meter run result $(\mathrm{Y})$ the frequency distribution can be arranged as follows:

Table 3. 800 meter Run Result Frequency Distribution List in Group Interval Exercise Method with High Endurance Ability (A3B1)

\begin{tabular}{cccccc}
\hline No & Value Interval & F & X & F.X & F Relative \\
\hline 1 & $124.14-125.26$ & 2 & 124.70 & 249.3975 & $20.00 \%$ \\
2 & $125.27-126.39$ & 2 & 125.83 & 251.6525 & $20.00 \%$ \\
3 & $126.40-127.51$ & 3 & 126.95 & 380.86125 & $30.00 \%$ \\
4 & $127.52-128.65$ & 3 & 128.09 & 384.25875 & $30.00 \%$ \\
& JUMLAH & 10 & & & $100 \%$ \\
\hline
\end{tabular}

From the results of the 800 meter run test that was collected from 10 samples in the Interval exercise group with High Endurance ability (A3B1) Unipatti FKIP Penjaskesrek students, it turns out the score range $124.14-125.26$ there are 2 people or $20 \%$, the score 125.27 126.39 there are 2 people or $20 \%$, scores 126.40 - 127.51 there are 3 people or $30 \%$, and scores 127.52 - 128.65 there are 3 people or $30 \%$.

3.4 1800 meter Run RResult Low Fartlek Exercise Group Method (A1B2).

Based on the research data of the 800 meter run on 10 students in the Fartlek training group with Low Endurance ability (A1B2) the lowest score was 124.05 and the highest score was 128.66 so the range was 4.61 . From the statistical calculation, the average deviation was 126.23 ( $\mathrm{s}$ ) amounting to 1.43 and variance of 2.05 and to give an idea of the frequency distribution of the 800 meter run result $(\mathrm{Y})$ the frequency distribution can be arranged as follows:

Table 4. 800 meter Running Frequency Distribution List in the Fartlek Exercise Group with Low Endurance Capability (A1B2)

\begin{tabular}{cccccc}
\hline No & Value Interval & F & X & F.X & F Relative \\
\hline 1 & $124.05-125.19$ & 2 & 124.62 & 249.2425 & $20.00 \%$ \\
\hline
\end{tabular}




\begin{tabular}{cccccc}
\hline 2 & $125.20-126.35$ & 3 & 125.77 & 377.32125 & $30.00 \%$ \\
3 & $126.36-127.50$ & 4 & 126.93 & 507.705 & $40.00 \%$ \\
4 & $127.51-128.66$ & 1 & 128.08 & 128.08375 & $10.00 \%$ \\
& TOTAL & 10 & & & $100 \%$ \\
\hline
\end{tabular}

From the results of the 800 meter run test collected from 10 samples in the group of Fartlek exercise methods with Low Endurance ability (A1B2) students of FKIP Unpatti Penjaskesrek, it turns out the score range $124.05-125.19$ there are 2 people or $20 \%$, the score 125.20 - 126.35 there are 3 person or $30 \%$, score 126.36 - 127.50 there are 4 people or $40 \%$, the score $127.51-128.66$ there is 1 person or $10 \%$.

3.5 1800 meter Running Result in a Group of Continuous Exercise Methods with Low Durability (A2B2)

Based on the research data of the 800 meter run on 10 students in the continuous exercise method group with Low Endurance ability (A2B2) the lowest score was 123.48 and the highest score was 127.12 so that the range was 3.64 From the statistical calculation, the average deviation was 125.29 ( $\mathrm{s}$ ) amounting to 1.22 and a variance of 1.48 and to give an illustration of the frequency distribution of the 800 meter run $(\mathrm{Y})$ can be arranged as the frequency distribution as follows.

Table 5. 800 meter Running Frequency Distribution List in The Continuous Exercise Method with Low Endurance Capability (A2B2)

\begin{tabular}{cccccc}
\hline No & Value Interval & F & X & F.X & F Relative \\
\hline 1 & $123.48-124.38$ & 2 & 123.93 & 247.86 & $20.00 \%$ \\
2 & $124.39-125.29$ & 2 & 124.84 & 249.68 & $20.00 \%$ \\
3 & $125.30-126.20$ & 4 & 125.75 & 503 & $40.00 \%$ \\
4 & $126.21-127.12$ & 2 & 126.67 & 253.33 & $20.00 \%$ \\
& TOTAL & 10 & & & $100 \%$ \\
\hline
\end{tabular}

From the results of the 800 meter running test collected from 10 samples in the group of continuous exercise methods with the ability of Low Endurance (A2B2) students of FKIP Unpatti Penjaskesrek, it turns out the score range is $123.48-124.38$ there are 2 people or $20 \%$, scores 124.39 - 125.29 there are 2 people or $20 \%$, scores $125.30-126.20$ there are 4 people or $40 \%$, scores $126.21-127.12$ there are 2 people or $20 \%$.

\subsection{800-meter Run Results for Low Durability Interval Exercise Method (A3B2).}

Based on the research data of the 800 meter run on 10 students in the Interval training group with Low Endurance ability (A3B2) the lowest score was 123.05 and the highest score was 126.39 so that the range was 3.34 . From the statistical calculation, the average deviation was 124.19 ( s) amounting to 1.09 and variance of 1.19 and to give an illustration of the frequency distribution of the 800 meter run $(\mathrm{Y})$ can be arranged as the frequency distribution as follows. 
Table 6. 800 meter Running Frequency Distribution List in The Group of Low Endurance Interval Exercise Methods (A3B2)

\begin{tabular}{cccccc}
\hline No & Value Interval & F & X & F.X & F Relative \\
\hline 1 & $123.05-123.88$ & 4 & 123.46 & 493.85 & $40.00 \%$ \\
2 & $123.89-124.71$ & 3 & 124.30 & 372.8925 & $30.00 \%$ \\
3 & $124.72-125.55$ & 2 & 125.13 & 250.265 & $20.00 \%$ \\
4 & $125.56-126.39$ & 1 & 125.97 & 125.9725 & $10.00 \%$ \\
& TOTAL & 10 & & & $100 \%$ \\
\hline
\end{tabular}

From the results of the 800 meter run test collected from 10 samples in the group of Low Endurance Interval exercise methods (A3B2) students Unipatti FKIP Penjaskesrek, it turns out the score range $123.05-123.88$ there are 4 people or $40 \%$, the score $123.89-124.71$ there are 3 people or $30 \%$, scores $124.72-125.55$ there are 2 people or $20 \%$, the score $125.56-126.39$ there is 1 person or $10 \%$.

\section{Discussion}

A good coach has the ability to transfer his/her knowledge to the pupils, to the athletes [15]. Jowett and Lavallee (2007: 118) stated "the significance of the coach to the performance, investment, and cognitive and emotional experiences of athletes is readily apparent to anyone who has played or watched competitive sport". Based on the description of the results of the analysis, testing the hypothesis and the effect of the exercise method and the resistance to the results of the 800 meter run that has been carried out, it can be explained that the results of data analysis and research hypothesis testing have been carried out using a one-way analysis of variance (ANAVA) and two lanes. First, the test uses a one-way Anava analysis approach, which is to test how much the difference between treatment groups is the farylek exercise method with a group of continuous exercise methods (A1 x A2), treatment group fartlek exercise method with interval exercise method group (A1 x A3) and the treatment group of the continuous exercise method with the interval exercise method group (A2 x A3), which was continued using the t-dunnet test.

Both tests used a two-way Anava analysis approach, namely testing how much the difference between groups of treatment methods and endurance treatment included differences in groups of students trained using the fartlek exercise method with groups of students trained using continuous exercise methods that have endurance abilities high (A1B1 x A2B1), a group of students trained using the fartlek exercise method with a group of students trained using interval exercise methods that have high endurance ability (A1B1 x A3B1) and groups of students trained using the continuous exercise method with groups of students trained to use interval exercise method that has high durability (A2B1 x A3B1). The group of students trained using the fartlek training method with a group of students trained using a continuous exercise method that has low endurance ability (A1B2 x A2B2), a group of students trained with the fartlek exercise method with a group of students trained with interval exercise methods with power abilities low resistance (A1B2 x A3B2) and groups of students trained with continuous exercise methods with groups of students trained with interval training methods 
with low endurance ability (A2B2 x A3B2). And the interaction between the two groups between training methods and endurance $(\mathrm{A} \times \mathrm{B})$.

\section{Conclusion}

Drawing conclusions is based on the findings of the $2 \times 3$ factorial experiment research, with independent variables namely exercise methods including; fartlek exercise method, continuous exercise method, and interval exercise method and the moderate variable is endurance and the dependent variable is the result of 800 meters run. The conclusions in this study are in accordance with the submission of hypotheses, from the results of hypothesis testing conducted can be concluded that:

a. There is a difference between the fartlek exercise method and the continuous exercise method on the results of the 800 meter run on the students of the Health and Recreation Health and Education Study Program at the Universitas Pattimura Ambon.

b. There is a difference between the fartlek exercise method and the interval exercise method on the results of the 800 meter run on the students of the Health and Recreation Health and Education Study Program at the Universitas Pattimura Ambon.

c. There is no difference between the continuous exercise method and the interval exercise method on the results of the 800 meter run on the students of the Health and Recreation Health and Education Study Program at the Universitas Pattimura Ambon.

d. There is an influence of the interaction between the exercise method and the resistance to the results of the 800 meter run on the students of the Health and Recreation Health and Education Study Program at the Universitas Pattimura Ambon.

e. There is a difference in the results of the 800 meter run between the fartlek exercise method using high endurance and the continuous exercise method using high endurance in students of the Health and Recreation Health and Education Study Program at the Universitas Pattimura Ambon.

f. There are differences in the results of the 800 meter run between the fartlek exercise method using high durability with the interval exercise method using high endurance in students of the Health and Recreation Health and Education Study Program at the Universitas Pattimura Ambon.

\section{Refferences}

[1] S. Jowett, 'The coach-athlete partnership', Psychologist. 2005.

[2] S. Jowett, 'Coaching effectiveness: the coach-athlete relationship at its heart', Current Opinion in Psychology. 2017.

[3] J. Lyle, Chapter 12: Where are all the women coaches? 2002.

[4] S. X. Yang and S. Jowett, 'Psychometric properties of the Coach-Athlete Relationship Questionnaire (CART-Q) in seven countries', Psychol. Sport Exerc., 2012.

[5] C. M. Behan, 'A Comprehensive Understanding of The Coach-Athlete Relationship: A Post- Secondary Canadian Team Sport Perspective', University of Victoria, 2002.

[6] W. Gilbert, J. Côté, and C. Mallett, 'Developmental Paths and Activities of Successful Sport Coaches', Int. J. Sports Sci. Coach., 2006. 
[7] L. A. Boyce, R. J. Jackson, and L. J. Neal, 'Building successful leadership coaching relationships: Examining impact of matching criteria in a leadership coaching program', J. Manag. Dev., 2010.

[8] L. A. Boyce, R. Jeffrey Jackson, and L. J. Neal, 'Building successful leadership coaching relationships', J. Manag. Dev., 2010.

[9] E. Bos, 'Coach', Pharmaceutisch Weekblad, 2011.

[10] T. F. Prastiwi, 'Developmental and Clinical Psychology', J. Psychol. Univ. Negeri Semarang, 2013.

[11] J. W. Creswell, Educational Research: Planning, Conducting and Evaluating Quantitative and Qualitative Research. London: Pearson, 2012.

[12] J. W. Creswell, Qualitative Inquiry and Research Design: Choosing Among Five Approaches, vol. 2nd ed. Thousand Oaks: Sage Publication, 2007.

[13] Budiyono, Metodologi Penelitian Pendidikan. Surakarta: UNS Press, 2003.

[14] M. E. Kite and B. E. Whitley, Principles of Research in Behavioral Science. 2018.

[15] A. S. Szabo, 'WHAT IS THE MEANING OF SPORT COACHING? (Expectations, possibilities, realities)', Sport SPA, 2012. 